DJS Vol. 43 (1) (2021) pp. 17-27 ISSN: 1012-5965

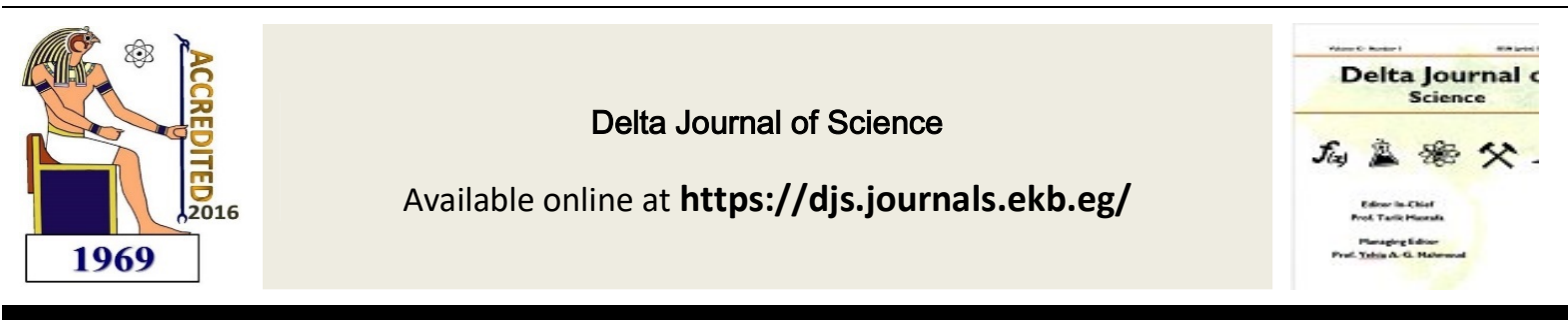

Research Article

CHEMISTRY

\title{
Photophysical Behavior and Sensing Response of Chalcone Containing Pyrene moeity
}

Marwa N. El-Nahass, Tarek A. Fayed*, Saleh Abd Elazim, Doaa F. Draz, Fathy Hassan

Department of Chemistry, Faculty of Science, Tanta University, Tanta, Egypt

${ }^{*}$ Corresponding Author: Dr. Tarek A. Fayed

E-mail: tfayed2013@gmail.com

\section{KEY WORDS}

Dyes,

solvatochromism, optical materials, surfactants, sensors

\section{ABSTRACT}

$\mathrm{D}-\pi-\mathrm{A}$ dye composed of pyrene and thiophene units was synthesized and characterized using elemental, FT-IR, and mass analyses. The solvatochromic response was investigated in different solvents of various polarities. Additionally, the inclusion characteristic of the investigated dye was studied in different organized assemblies of three surfactants. The spectral changes suggested that the dye would be useful to study the critical micelle concentrations of the studied assemblies systems. Furthermore, the absorption and emission spectra are sensitive towards $\mathrm{H}^{+}$, $\mathrm{Co}^{2+}, \mathrm{Ni}^{2+}, \mathrm{Cd}^{2+}, \mathrm{Pb}^{2+}$, and $\mathrm{Zn}^{2+}$ ions owing to acido- and metallochromic behaviors. These results suggest that the investigated dye would be potential candidate for polarity sensors, probe to characterize microenviromental polarity of the surfactants, and sensor for metal ions and $\mathrm{H}^{+}$proton.

\section{Introduction}

Solvatochromic and charge transfer behaviors of $\mathrm{D}-\pi-\mathrm{A}$ dyes have received a considerable attention owing to a growing interest in different fields $[1,2]$. These dyes have used for determination of the solvent polarity [3], as colorimetric 
chemosensors for volatile organic compounds $[4,5]$, photo- and electroluminescent materials in dye lasers [6,7], switchable viscosity probes [8], dual-ion-switched molecular brakes [9], dye sensitized solar cells [10-12] and nonlinear optical materials [13]. Among of theses dyes, chalcones are great of interest chemo types for both chemists and physicists, due to their high natural abundance, easy synthesis, and their diverse biological activities. Additionally, they have been used as photorefractive polymers, holographic recording materials, and fluorescent probes for different metal ions sensing [14-20]. On the other hand, the polycyclic aromatic hydrocarbons such as naphthalene, phenanthrene, and pyrene have strong absorption cross section, excellent emission properties, and long excited state lifetime compared to simple phenyl analogue [21, 22].

In this study, we designed new D$\pi-\mathrm{A}$ dye composed of polycyclic aromatic hydrocarbon (pyrene) and thiophene as chromophores units. The import of those aromatic units as terminal groups will influence the polarity and viscosity environment of the fluorescence characteristics of the dye. Further, introducing polycyclic aromatic ring will influences the noncentrosymmetric crystal packing of dye owing to $\pi-\pi$ staking interaction. In addition, the molecular hyperpolarizability is strongly influenced not only by the electronic effect but also by the steric effect of the substituent.

The molecular design of the synthesized dye is shown in Fig. 1. The dye was abbreviated as follow: 3-(4,5dihydropyren-2-yl)-1-(thiophen-2-yl) prop-2 en-1-one (PyTPO). The solvent effect on the investigated dye was discussed. The spectral behavior in organized assemblies of micelles (SDS, CTAB and, TX-100) was also studied to evaluate the ICT emission and inclusion behaviors to explore its probing ability to characterize the properties of these media. Further, the sensing response towards different metal ions such as $\mathrm{Co}^{2+}, \mathrm{Ni}^{2+}$, $\mathrm{Cd}^{2+}, \mathrm{Pb}^{2+}$, and $\mathrm{Zn}^{2+}$ was investigated. In addition, the acidochromic behavior of the investigated dye was studied using Hammett's acidity function scale $\left(\mathrm{H}_{\mathrm{o}}\right)$.

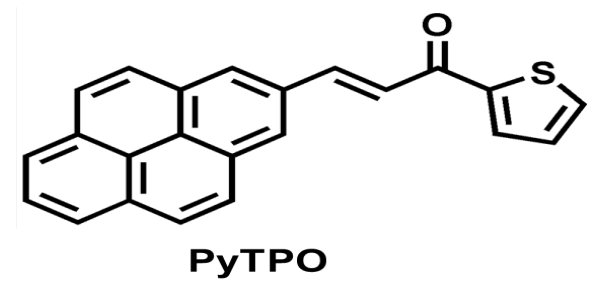

Fig.1.Chemicals structures of the investigated dye.

\section{Experimental}

\subsection{Materials}


All chemicals were purchased from Merck-Aldrich Chemicals and used as received without further purification: 2acetyl thiophene, 9-pyrene carbaldehyde, sodium dodecyl sulfate (SDS), cetyltrimethyl ammonium bromide (CTAB), Triton X-100 (TX-100)], metal salts $\left(\mathrm{CoCl}_{2} \cdot 6 \mathrm{H}_{2} \mathrm{O}, \mathrm{NiCl}_{2} \cdot 6 \mathrm{H}_{2} \mathrm{O}, \mathrm{CdCl}_{2}\right.$, $\mathrm{PbCl}_{2}$, and $\mathrm{ZnCl}_{2}$ ), and solvents (methanol $(\mathrm{MeOH})$, acetonitrile $(\mathrm{ACN})$, dichloromethane $\left(\mathrm{CH}_{2} \mathrm{Cl}_{2}\right)$, benzene (Benz) and n-heptane (Hep). All solvents were found to be non-fluorescent in the scanned range.

\section{2. Methods}

The FT-IR spectra were recorded $\begin{array}{lll}\text { by JASCO FT/IR-4100 } & \end{array}$ spectrophotometer using $\mathrm{KBr}$ Pellets within the range 4000 to $400 \mathrm{~cm}^{-1}$. Mass spectrum was measured on a Finnigan MAT 8222 EX mass spectrometer at 70 $\mathrm{eV}$. The elemental microanalyses of the investigated dye were performed using Perkin-Elmer 240 CHNS Elemental analyzer. Steady-state absorption and emission spectral measurements were carried out using a Shimadzu UV3101PC scanning spectrophotometer and Agilent Cary Eclipse Fluorescence Spectrophotometer, respectively. In all experiments, $2 \times 10^{-5} \mathrm{M}$ solutions were used and handled under dim light at room temperature. The fluorescence quantum yield $\left(\Phi_{f}\right)$ of the investigated dye was measured using the optically diluted solution to avoid the reabsorption effect (absorbance at excitation wavelength $\leq 0.1$ ), relative to the method with a solution of quinine sulfate in $0.5 \mathrm{~mol} / \mathrm{dm}^{3}$ $\mathrm{H}_{2} \mathrm{SO}_{4}(\Phi=0.55)[23]$.

\subsection{Synthesis}

The investigated dye was synthesized following the protocol of previous report [24]. The molecular structure was confirmed by FT-IR, mass spectroscopy, and elemental analysis. The FT-IR spectrum showed sharp bands at vibrational frequencies within the range $1587 \mathrm{~cm}^{-1}$ and $1643 \mathrm{~cm}^{-1}$ characteristic for the ethylenic double bond and carbonyl group, respectively, Fig. 2. The spectra showed bands at $917-1085 \mathrm{~cm}^{-1}$ owing to out of plane bending vibration of $\mathrm{CH}=\mathrm{CH}$. In addition, weak bands are observed in the range $3423-3448 \mathrm{~cm}^{-1}$ corresponding to stretching vibrations of the aliphatic $\mathrm{C}$ $\mathrm{H}$ bond. The mass spectrum of the investigated dye shows molecular ion peaks at the desired positions: $\mathrm{m} / \mathrm{z}=338$, Fig.3. The obtained molecular ion peaks showed that $\mathrm{m} / \mathrm{z}$ is equivalent to the molecular weight of the proposed compounds. Hence, $\mathrm{m} / \mathrm{z}$ value confirms the molecular weight of the investigated dye. Elemental analysis: calcd for $\mathrm{C}_{23} \mathrm{H}_{14} \mathrm{SO}$; C, 81.65; H, 4.14 and S, 9.47; 
Found: C, 85.52; H, 4.17 and S, 9.76, mp $170{ }^{\circ} \mathrm{C}$.

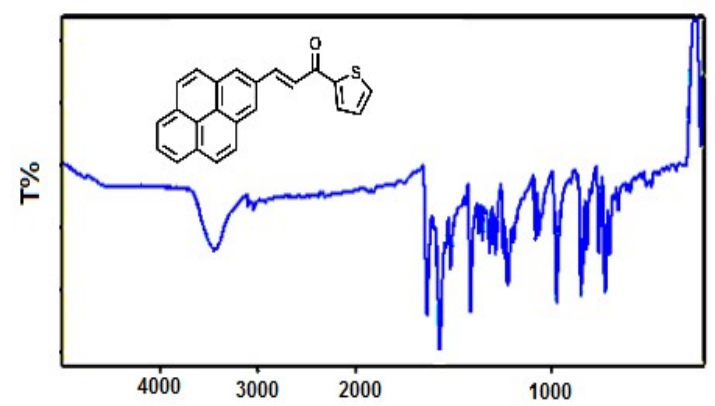

Fig. 2: FT-IR spectrum of the investigated dye.

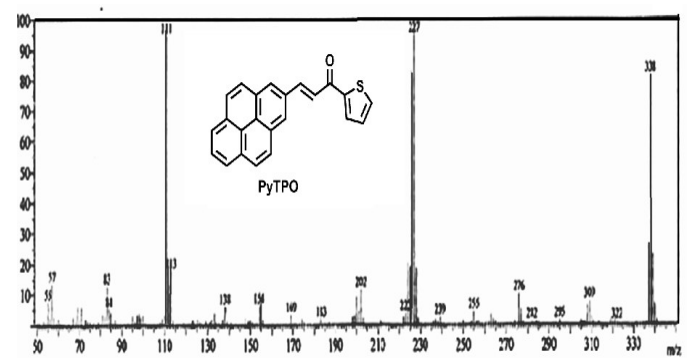

Fig.3: Mass spectrum of the investigated dye.

\section{Results and Discussion}

a. Solvatochromic behavior of the investigated dye

Steady state absorption and fluorescence spectra of the investigated dye have been studied in solvents of different polarities at room temperature, Fig. 4 (a), and the corresponding spectroscopic data were summarized in Table 1. As can be seen, the absorption spectra of PyTPO showed vibrational structure in all used solvents owing to the planar structure of the pyrene moiety of as shown in Fig.5. In addition, the absorption band of the investigated dye undergoes red shifts with changing the solvent polarities. This absorption band may be due to the intramolecular charge transfer from the aryl moiety (pyrene) to the carbonyl group via the ethylenic bridge (push-pull dye $\pi$ system).
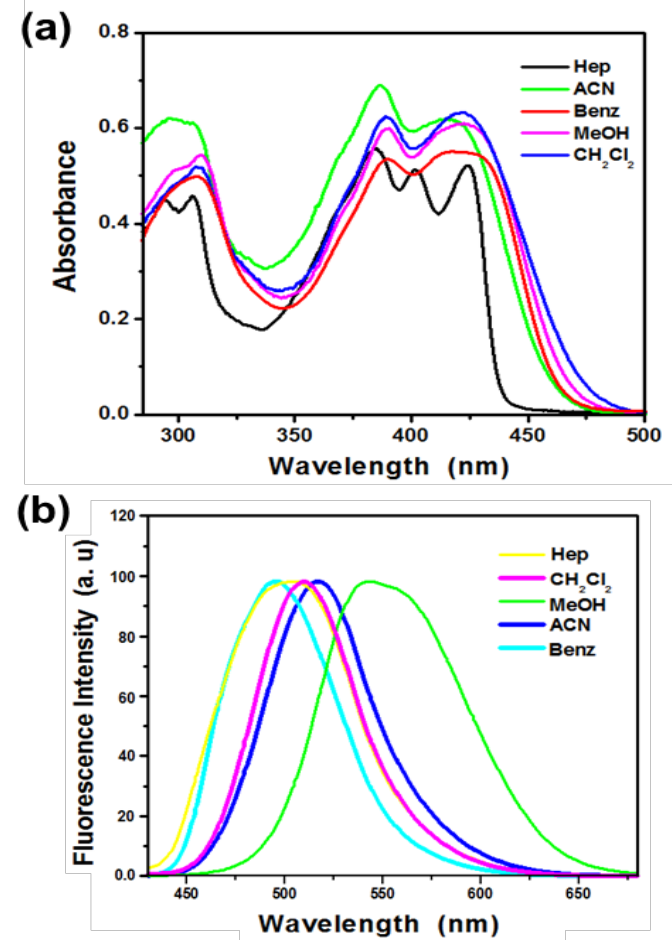

Fig. 4: Absorption (a) and emission (b) spectra in different polarities solvents of PyTPO.

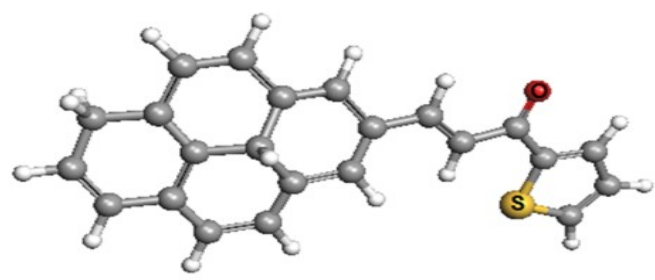

Fig.5: Optimized structures of the investigated dye.

As shown in Table 1, the absorption spectrum of the dye under investigation is less sensitive to the solvent polarity compared to the fluorescence spectra, indicating that the excited singlet states of PyTPO molecule have more polar character than its ground state. Further, 
emission spectra of the investigated dye are represented in Fig. 4 (b). The fluorescence spectrum suffers a strongly bathochromic shift as the solvent polarity is increased by $44 \mathrm{~nm}$, from $\mathrm{MeOH}$ to Hep, for PyTPO, indicating the ICT from the aryl moeity to the carbonyl group which takes place within the molecule in the singlet excited state $S_{1}$. This suggests that the molecule are solvated significantly in the $\mathrm{S}_{1}$ excited state, resulting in a bathochromic shift and observable difference in the dipole moment between the $\mathrm{S}_{1}$ excited state and the ground state $S_{o}$.

As the emission spectra of the investigated dye are strongly affected by the solvent in aspects of emission intensity and wavelength, the visual effect of the polarity dependence of the fluorescence of PyTPO was examined. PyTPO dye gave an interesting feature via the irradiation at $\lambda_{\mathrm{ex}}=365 \mathrm{~nm}$ in all used solvents. It can be seen clearly that with increasing the solvent polarity, the fluorescence of PyTPO is greatly intensive in protic and aprotic solvents and quenched significally in non-polar solvent such as Hep and Benz, therefore PyTPO can be used as polarity probes.

A cursory glance on the data reported in Table 1, it was found that the fluorescence quantum yields $\left(\Phi_{f}\right)$ are highly sensitive to the solvent polarity and the ring size. The $\Phi_{f}$ values of PyTPO increase by 1.98 folds on going from Hep to $\mathrm{MeOH}$. The results indicate that PyTPO is highly fluorescent dye.

Table 1: Dipole moments and correlation factor $(R)$ of PyTPO measured in various solvents at $25^{\circ} \mathrm{C}$.

\begin{tabular}{|c|c|c|c|c|c|}
\hline Solvent & $\begin{array}{c}\lambda_{\max }^{\mathrm{a}} \\
(\mathrm{nm})\end{array}$ & $\begin{array}{l}\lambda_{\max }^{\mathrm{f}} \\
(\mathrm{nm})\end{array}$ & $\Phi_{\mathrm{f}}$ & $\begin{array}{l}\mu_{\mathrm{g}} \\
\text { (D) }\end{array}$ & $\begin{array}{l}\mu_{\mathrm{e}} \\
\text { (D) }\end{array}$ \\
\hline Нер & 385,424 & 501 & 0.05 & \multirow{5}{*}{1.6} & \multirow{5}{*}{21.9} \\
\hline Benz & 390,421 & 495 & 0.34 & & \\
\hline $\mathrm{CH}_{2} \mathrm{Cl}_{2}$ & 389,421 & 510 & 0.55 & & \\
\hline $\mathrm{ACN}$ & 387,417 & 517 & 0.56 & & \\
\hline МeOH & 389,423 & 545 & 0.099 & & \\
\hline
\end{tabular}

Also, the difference in the dipole moments between the excited singlet $\left(\mu_{e}\right)$ and ground $\left(\mu_{g}\right)$ states can be determined using Bakhshiev's and Kawski-Chamma-Viallet's [25]. The Onsager cavity radius, $a$, was estimated following geometry optimization of the investigated dye (with the help of ArgusLab 4.0 software and free HyperChem 8.03 software using PM3 Hamiltonian method) and comes out to be $6.4 \mathrm{~A}^{\mathrm{o}}$.

The dipole moments of the investigated dye in both ground and excited states have been estimated. As can be seen, the dipole moment of the investigated dye in the ground state was smaller than that reported in the excited state, confirming the existence of a more 
relaxed excited state, due to ICT favored by the cooperative effects of the aryl moiety as a donor and the carbonyl fragment as an acceptor. The large difference between the dipole moments of ground and excited states is consistent with the higher extent of contribution of dipole-dipole interaction towards the stability of excited state than that of ground state. This result suggests that this dye can serve as good candidate components of nonlinear optical materials.

\subsection{Effect of surfactant on the spectral behavior of the investigated dye}

The spectral properties of the investigated dye have been studied in cationic, CTAB, anionic, SDS, and neutral, TX-100, micellar media. Fig. 6 shows the absorption spectra of the investigated dye in the absence and presence of different concentrations of the used surfactant. Generally, it was found that the absorption spectra for PyTPO increase with increasing the concentrations of the used surfactants with hypsochromic shift. The absorption bands in water (located at $440 \mathrm{~nm}$ ) are blue shifted by $5 \mathrm{~nm}, 13 \mathrm{~nm}$, and $16 \mathrm{~nm}$ on adding different concentrations of CTAB, SDS, and TX-100, respectively.

The fluorescence band maximum of PyTPO located at $539 \mathrm{~nm}$ in water is strongly blue shifted ca. 32, 16 and $38 \mathrm{~nm}$ on adding CTAB, SDS, and TX-100, respectively, which are very close to the critical micelle concentration (CMC). The spectral shift is accompanied by a great enhancement in the fluorescence intensity, confirming the stronger binding between the used surfactants and PyTPO dye. The continuous enhancement in the fluorescence intensity is attributed to the passage of dye molecule from the aqueous bulk solution to the palisade layer of the micelle. The decrease in polarity of the microenvironment around the dye molecule results in the reduction of the non-radiative transfer rate from the ICT state to the low-lying singlet or triplet state due to the increase in the energy gap between them, which leads to an increase in emission intensity. In CTAB and SDs, the dipolar excited PyTPO molecules will be transferred to a less-polar hydrophobic environment, and their head groups try to increase the fluorescence intensity by pushing the dye molecule towards nonaqueous environment. However, in the case of TX-100, the driving force is hydrophobic, which makes the dye molecule more compact, more rigid and less mobile.

The situation is some extent different on recording the fluorescence spectra of PyTPO in the presence of CTAB and SDS. Moreover, more significant reductions were noticed in the 
fluorescence intensities. It seems that the dye molecules located at the micellewater interface, showing the quenching role of water.
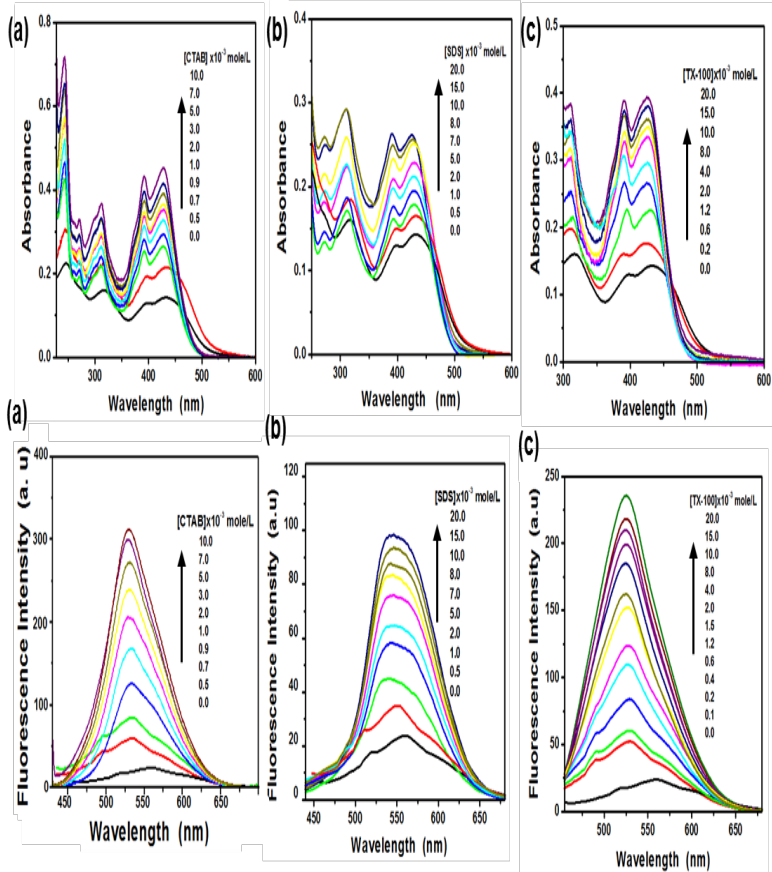

Fig.6: Absorption and fluorescence spectra of PyTPO measured in CTAB (a), SDS (b), and TX-100 (c) micellar solutions, respectively.

\section{investigated dye}

In order to study the effect of acidity on the spectral behavior of PyTPO, the electronic absorption and emission spectra of $2 \times 10^{-5} \mathrm{~mol} / \mathrm{L}$ of the investigated dye were measured at different concentrations of sulfuric acid, Fig.7. The absorption spectra of the investigated dye changed dramatically upon increasing the concentration of sulfuric acid (from $10 \%$ to $98 \%$ ) with an observable change in color, Fig.8. As a representative example, PyTPO dye solution changes from faint yllow, to violet passing through faint blue color as the concentration of sulfuric acid was increased. Actually, the yellow color is recovered upon the addition of water solution, which is evidence for the reversibility of the prototropic equilibrium that takes place.

On the other hand, the fluorescence maximum of the neutral species which appears at $\lambda_{\max }^{\mathrm{f}}=562 \mathrm{~nm}$, is red-shifted by $21 \mathrm{~nm}$, at lower sulfuric acid concentrations (from $10 \%-40 \%$ ), however, at high concentrations (from $50 \%$ to $70 \%$ ), the fluorescence maximum is blue-shifted ( $\left.\lambda_{\max }^{\mathrm{f}}=485 \mathrm{~nm}\right)$. Two bands have been developed at 476 and $645 \mathrm{~nm}$, respectively, at very high concentrations $90 \%$ and $98 \%$. 


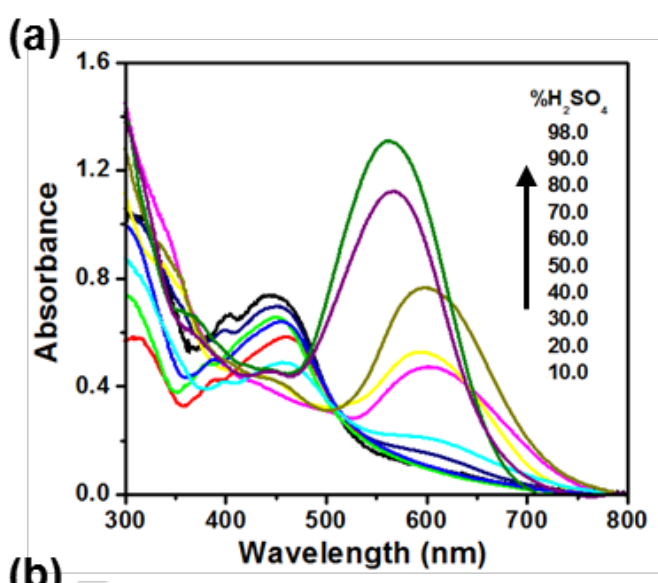

(b)

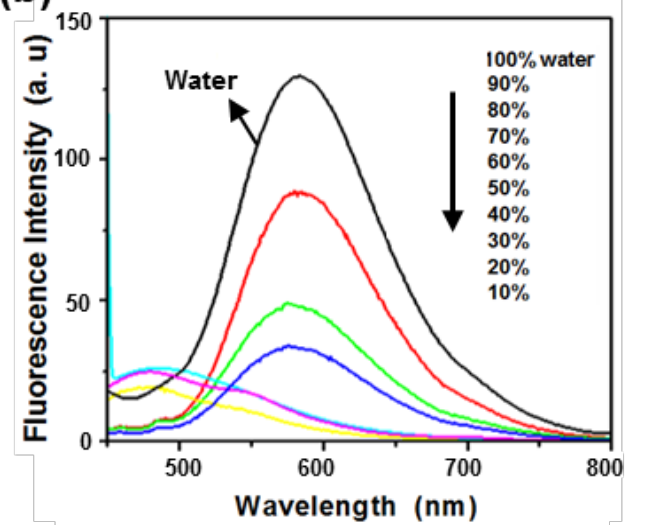

Fig.7: Absorption (a) and emission (b) spectra for PyTPO upon addition of different concentrations of sulfuric acid.

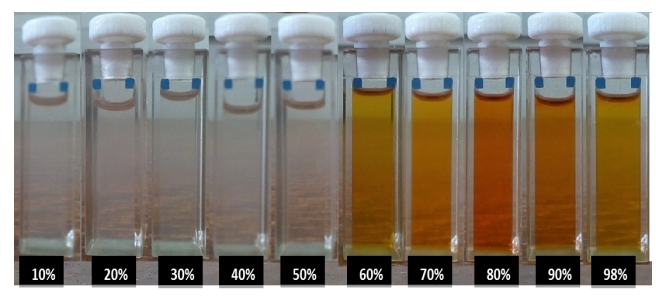

Fig. 8: Acidochromic behavior of PyTPO in sulfuric acid solutions.

\subsection{Metallochromic behaviors of the investigated dye}

The sensing ability of the investigated dye, towards the metal ions such as $\mathrm{Co}^{2+}, \mathrm{Ni}^{2+}, \mathrm{Cd}^{2+}, \mathrm{Pb}^{2+}$, and $\mathrm{Zn}^{2+}$ has been studied. Figure 9 shows the electronic absorption spectra of PyTPO in the absence and presence of different concentrations of the used metal ions in ethanolic solution. As shown, on adding $\mathrm{Co}^{2+}$ ions to $2 \times 10^{-5} \mathrm{M}$ dye solution, the absorption band maximum appearing at $425 \mathrm{~nm}$ decreases with appearance of a new visible absorption band at $656 \mathrm{~nm}$. This was accompanied by formation of isosbestic point at $466 \mathrm{~nm}$. Also, for the interaction of PyTPO with $\mathrm{Ni}^{2+}$, the absorption band maxima increase with formation of isosbestic point at $390 \mathrm{~nm}$. However, in case of adding different concentrations of $\mathrm{Pb}^{2+}$ to PyTPO solutions, the absorption band increases gradually with formation of a broad band at $489 \mathrm{~nm}$. The similar behavior for $\mathrm{Zn}^{2+}$ ion, at which a broad band at $500 \mathrm{~nm}$, has been observed. The obtained results could be explained on the basis of complex formation between the used metal ions and the investigated PyTPO through sulfur atom of thiophene moiety and the oxygen atom of the carbonyl group. This suggests that the investigated dye exhibit high sensitivity towards the used metal ions. 

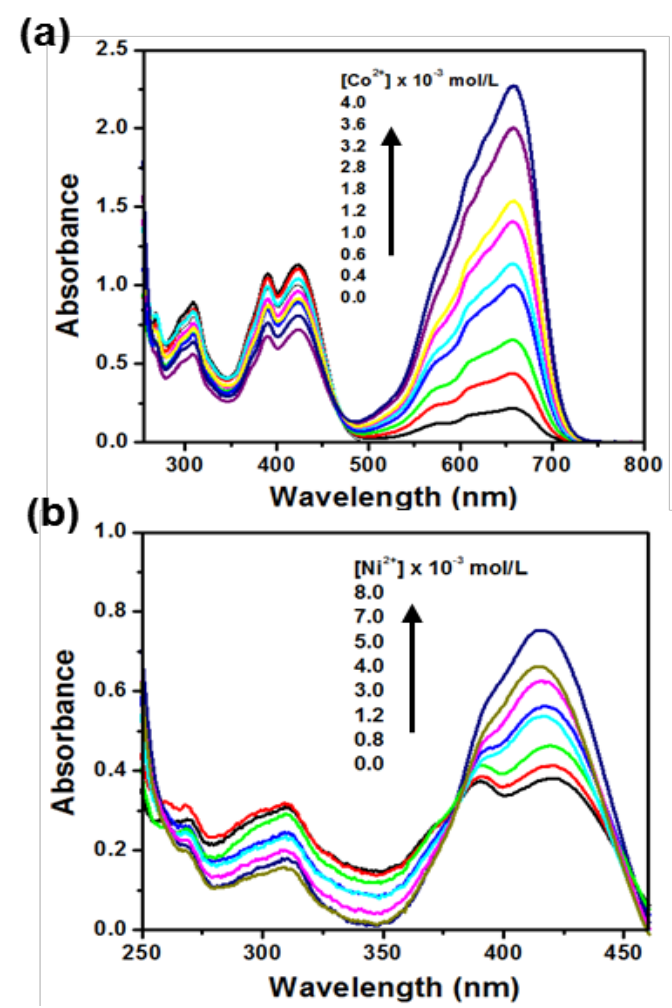

Fig. 9: The absorption spectra of PyTPO after addition of (a) $\left[\mathrm{Co}^{+2}\right]$ and (b) $\left[\mathrm{Ni}^{+2}\right]$ ions.

Figure 10 shows the emission spectra of PyTPO in the presence of different concentrations of the mentioned metal ions. The fluorescence band of the investigated dye observed at $553 \mathrm{~nm}$ in EtOH, was hypochromic shift on adding different concentrations of $\mathrm{Co}^{2+}, \mathrm{Ni}^{2+}$, and $\mathrm{Zn}^{2+}$ ions by $(6,14,3 \mathrm{~nm}),(9,5,3 \mathrm{~nm})$, and $(5,8,6 \mathrm{~nm})$, respectively, with a great quenching in the fluorescence intensity. Upon adding different concentrations of both $\mathrm{Pb}^{2+}$, and $\mathrm{Cd}^{2+}$ ions, the fluorescence spectra increase with bathochromic shift. The results confirm the complexation between the investigated dye and the mentioned metal ions.

The ground and excited state binding constants of $\mathrm{Co}^{2+}, \mathrm{Ni}^{2+}, \mathrm{Cd}^{2+}$, $\mathrm{Pb}^{2+}$, and $\mathrm{Zn}^{2+}$ complexes with the investigated dye were determined by employing Benesi Hildebrand equation [26], The obtained data indicates that $\mathrm{Cd}^{2+}$ is the strongest binding metal ions with the investigated chemosensor than the other tested metal ions, indicating that $\mathrm{Cd}^{2+}$ is the most effectively detected and the potential of the novel dye as highly efficient switchers for $\mathrm{Cd}^{2+}$ ions.

(a)

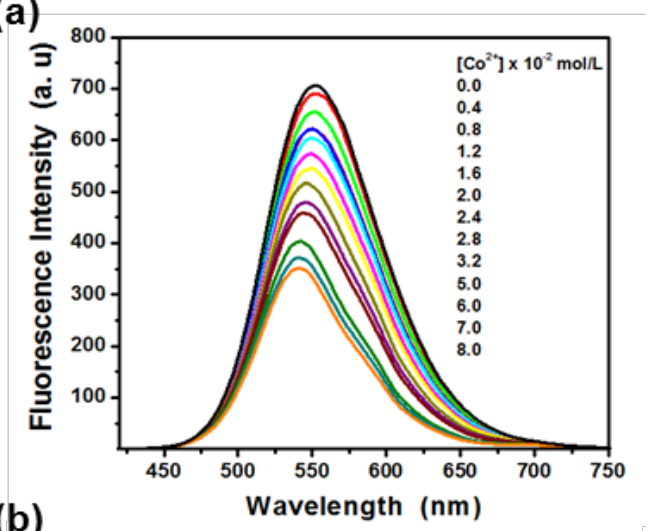

(b)

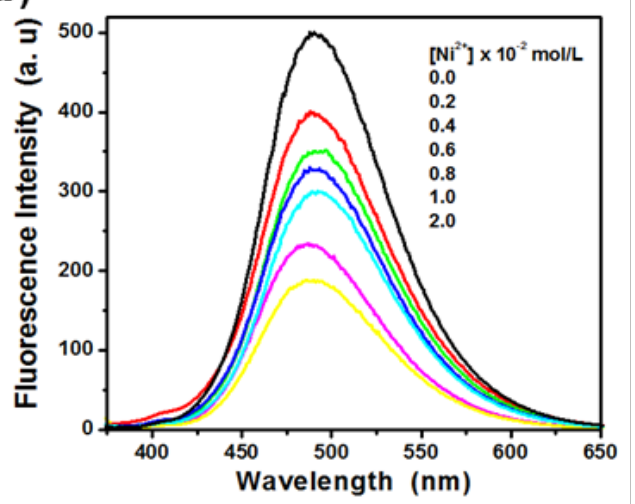

Fig.10: Emission spectra of PyTPO after addition of (a) $\left[\mathrm{Co}^{+2}\right]$ and (b) $\left[\mathrm{Ni}^{+2}\right]$ ions. 


\section{Conclusion}

Pyrene-thiophene dyes was successfully synthesized and characterized. Large excited state dipole moments were obtained from the fluorescence spectra, indicating the stabilization of the excited state in polar solvents owing to solvatochromic behavior. In addition, a change in the dye color in various solvents was observed, suggesting its potential as candidate probes for the identification of organic solvents. The investigated dye was used also to study the microenviromental polarity and evaluation of critical micelle concentrations of three different surfactants. Furthermore, acido- and metallo-chromic behaviors were observed from absorption and emission spectra with color change with efficient reversibility. These results suggest that the investigated dye would be potential candidate for polarity sensors, probes to characterize microenviromental polarity and critical micelle concentrations of surfactants, and sensors for metal ions and $\mathrm{H}^{+}$proton.

\section{References}

1. A. Klymchenko, Acc. Chem. Res., 2017, 50,366.

2. B. Carlotti, A. Cesaretti, O. Cannelli, T. Giovannini, C.hiaraCappelli, C. Bonaccorso, C. Fortuna, F. Elisei, A.
Spalletti, J. Phys. Chem. C, 2018, 122, 2285.

3. E.Verbitskiy, E. Cheprakova, J. Subbotina, A. Schepochkin, P. Slepukhin, G. Rusinov, V. Charushin, O. Chupakhin, N. Makarova, A. Metelitsa, V. Minkin, Dye Pigments, 2014, 100, 201.

4. Bamfield P. (2001) Chromic phenomena: technological application of colour chemistry. The Royal Society of Chemistry, Cambridge.

5. M. Janzen, J. Ponder, D. Bailey, C. Ingison, K. Suslick, Anal. Chem. 2006, 78, 3591 .

6. V. Anthonov, K. Hohla, Appl. Phys. B, 1983, 32, 9 .

7. S. Speiser, N. Shakkour, Appl. Phys. B 1985, 38, 191.

8. A. Silva, H. Gunaratne, T. Gunnlaugsson, A. Huxley, C. McCoy, J. Rademacher, T. Rice, Chem. Rev. 1997, 97,1515.

9. D. Zhang, Q. Zhang, J. Su, H. Tian, Chem. Commun. 2009, 1700.

10. J. Sansregret, J. Drake, W. Thomas, M. Lesiecki, Appl Opt 1983, 22, 573.

11. B. Liu, W. Zhu, Q. Zhang, W. Wu, M. Xu, Z. Ning, Y. Xie, H. Tian, Chem. Commun.2009, 1766.

12. E. Verbitskiy, E. Cheprakova, J. Subbotina, A. Schepochkin, P. Slepukhin, G. Rusinov, V. Charushin, O. Chupakhin, N. Makarova, A. Metelitsa, V. Minkin, Dye Pigments, 2014, 100, 201. 
13. X. Zhang, B. Chen, X. Lin, Q. Wong, C. Lee, H. Kwong, S. Lee, S. Wu, Chem. Mater., 2001, 13, 1565.

14. Y. Wei,G. Qin,W. Wanga, W. Biana, S. Shuang, C.Dong, J. Lumin., 2011, 131, 1672.

15. G. Gillispie, Adv. Chem., 1993, 236, 89.

16. M. N. El-Nahass, D. M. Abd El-Aziz, T. A. Fayed, Sensor Actuat B-Chem., 2014, 205, 377.

17. M. El-Nahass, T. Fayed, Appl. Organomet. Chem., 2017, 31, 1.

18. Marwa N. El-Nahass, Tarek A. Fayed, Mohamed H. Shaaban, Fathy M. Hassan, Sens. Actu. B Chem., 2015, 210, 56.

19. Faten M. Atlam, Marwa N. El-Nahass, Eman A. Bakr, Tarek A. Fayed, Appl. Organomet. Chem., 2017.
20. M. Gaber, Tarek A. Fayed, Marwa N. El-Nahass, H.A. Diab, Mohammed M. El-Gamil, Appl Organometal Chem., 2019, 33, e5133

21. R. Liu, H. Ran, Z. Zhao, X. Yang, J. Zhang, L. Chen, H. Sun, and J. Hu, ACS Omega, 2018, 3, 5866.

22. E. Gutiérrez, M. Percino, V. Chapela, M. Cerón, J. Maldonado, G. Ortiz, Materials, 2011, 4, 562.

23. J. Demas, G. Crosby, J. Phy. Chem..1971, 75, 991.

24. T. Fayed, M. El-morsi, M. ElNahass, J. Photochem. Photobio. A, 2011, 224, 38.

25. a) N. Bakshiev, Opt. Spectosc., 1964, 16, 821; b) A. Kawski, Acta Phys. Pol., 1966, 29, 507; c) A. Chamma and P. Viallet, C. R. Seances Acad. Sci., Ser. C, 1970, 27, 1901.

26. M. Benesi, J Hildebrand, J. Am. Chem. Soc. 1949, 71, 2703

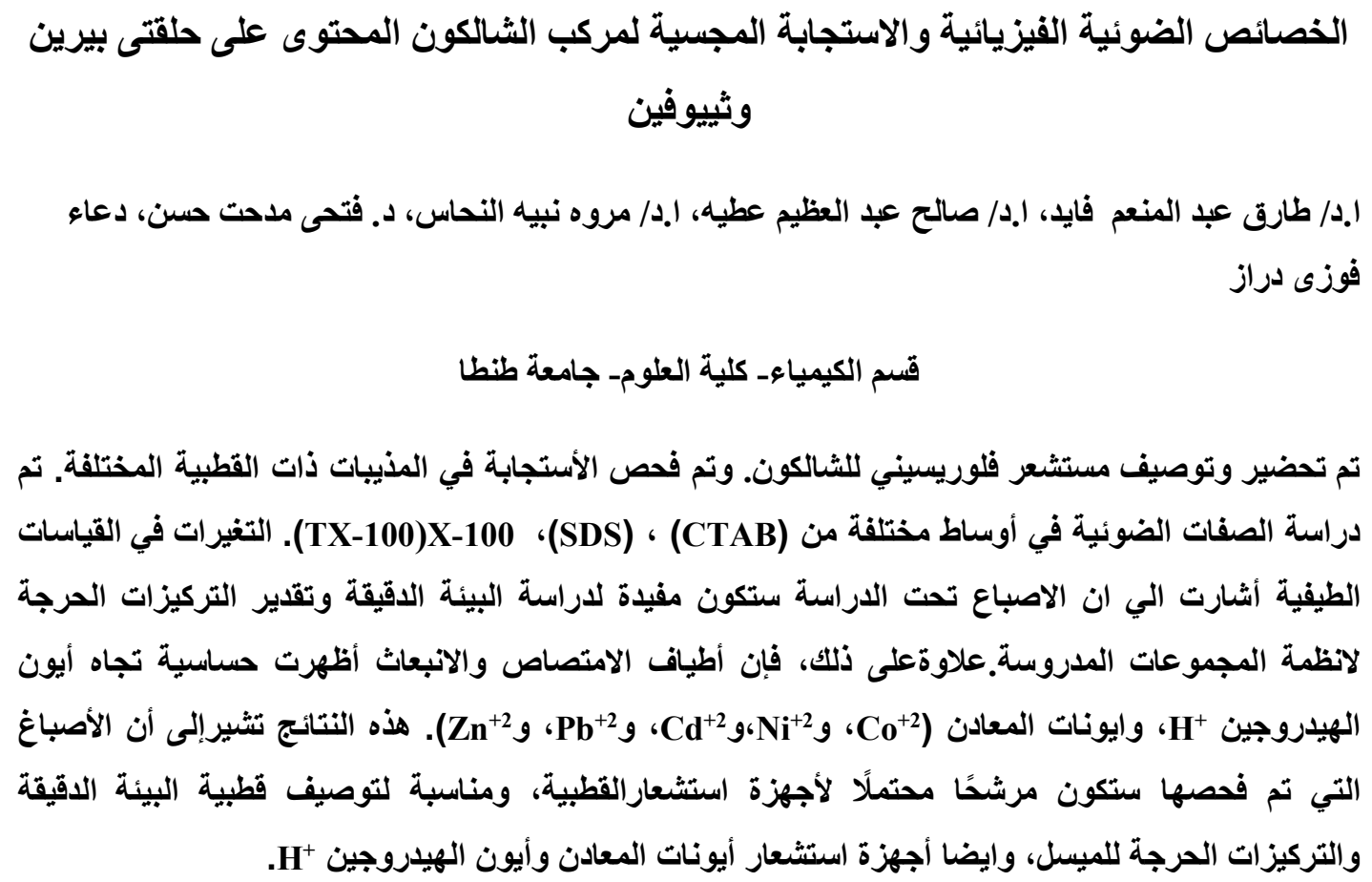

